http://www.jfas.info

\title{
STUDENT ACCEPTANCE OF EDUCATIONAL GAMES IN HIGHER EDUCATION
}

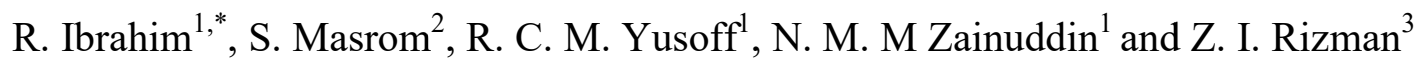

${ }^{1}$ Advanced Informatics School, UniversitiTeknologi Malaysia, 54100 Kuala Lumpur, Malaysia

${ }^{2}$ Faculty of Computer and Mathematical Sciences, UniversitiTeknologiMARA, Tapah 35400, Perak, Malaysia

${ }^{3}$ Faculty of Electrical Engineering, UniversitiTeknologi MARA, 23000 Dungun, Terengganu, Malaysia

Published online: 10 September 2017

\begin{abstract}
Studies of educational games (EG) are rapidly growing in recent years due to its promising potential for education. New generation are highly engaged with games technology resulted with many games produced from industry or research. Despite that, student acceptances on games are still low due to issues from both student and games side including effectiveness, matching with syllabus as well as games design. Therefore, it is crucial to understand the factors that contribute to student acceptance of EG in order to produce a better game.This study proposed and validated games acceptance framework with six factors. Data was collected with 180 university students and analyze usingdescriptive and inferential analysis. Learning Expectancy, Effort Expectancy, Attitude and Enjoyment were found significant. Games designers can leverage the issues concern with students in developing better games.
\end{abstract}

Keywords: educational games;acceptance; games for learning; game based learning.

Author Correspondence, e-mail: iroslina.k1@utm.my

doi: http://dx.doi.org/10.4314/jfas.v9i3s.62 


\section{INTRODUCTION}

\subsection{Studies on Educational Games}

Study on educational games (EGs) technology and applications have experienced significant development especially in the last decade. This is due to researchers' believe that educational games are able to enhance the traditional ways of teaching and learning (T\&L) as mentioned by several studies and reports [1-6]. Educational games also integrating fun elements to traditional ways of T\&L methodology, apart from highly engaging, motivated and immersive. Furthermore, games are indeed very popular among the younger generations due to their preferences on computer and internet technology. A new generation of learners grow up with advanced computer technology, high speed broadband, social networking applications and online videos are found to have different preferences in teaching and learning approaches [1, 7-8]. As mentioned in [9], new generations are more adventurous, having less retention and more multitasking. These characteristics of new learners instigate different and new learning approaches to better suit their preferences. It is common these days to see preschool students up to teenagers bring around their games gadget everywhere they go. Based on that matters, many researchers believe that integration of games technology into existing T\&L approaches may help transform learning process, stimulate students interest to learn and making teaching and learning more fun as well as effective [1,4-5,10-15].

In addition to that, games are said to be able to deliver various types of learning outcomes such as knowledge acquisition, cognitive process, affective outcomes, behavioral changes as well as social and soft skills [16]. Knowledge acquisition outcomes demonstrated in [17] whereby students who learn English using games gained more scores compared to students whom used traditional teaching method. Another study found that games to teach sexual relationships was more effective than the group whom did not use the games [18]. Studies on cognitive acquisition found that games are able to provide the required ability of cognitive process such as visual perception and memory[19-20].

Despite the promise of educational games and researchers efforts to encourage its use, games are still not widely accepted by stakeholders such as teachers, students and parents [21-25]. In [14] argued that acceptance of educational games are still lacking although there are many 
commercial off-the shelf educational games title available. This is happens both in formal education settings as well as informal settings. Students and teachers are still uncertain about the use of EG in teaching and learning. It is more important to understand the factors contribute to student's acceptance of educational games considering they are the main education stakeholders. Therefore, this study investigated the factors contribute to acceptance of educational games among students.

\section{BACKGROUND OF THEORIES}

\subsection{Theories of User Acceptance}

This section discusses the theoretical background of user acceptance of information systems and related studies. In [26]defined user acceptance as "demonstrable willingness within a user group to employ information technology for the tasks it is designed to support". It is built to understand the factors that contribute to user decision in accepting or use an information system. Generally, it explore on three important dimensions which are systems factors, user factors as well as organizational factors. Among the most common factors in user acceptance studies are usefulness, ease of use, social influence, facilitating conditions, enjoyment, attitudes and use background factors such as gender, age and experience.

User acceptance inquires about why people accept a system or how users perceive a particular system so that a better understanding of target users can be acquired. This will help the information systems designers to tailor their design based on user needs. It is because a highly user friendly system will not guarantee its acceptance if the users find that the systems is not useful for them. However, systems that are not that friendly might be used by the users for its usefulness. These are two most important factors regarding user acceptance of information systems [27]. In addition, there are also mediators and moderators that effect acceptance of information systems (IS) such as voluntary or mandatory use, social influence, facilitating conditions and so on. These factors are important to be understood by systems developers to fully leverage the success of IT implementation within an organisation, public usage or even leisure applications on the internet.

In information systems research, two most prominent theories are Technology Acceptance 
Model (TAM) by [27] and Unified Theory of Acceptance and Use of Technology (UTAUT) by [28]. Both theories were formulated and validated within information systems environment. In [27] have developed TAM based on several behavioural theories in sociology studies. TAM postulated that behavioural intention to use a particular technology is a very important factor that determines actual use of the systems. Behavioural intention is influenced by attitude towards usage whereby attitude is influenced by other external variables including usefulness and ease of use. TAM is among the most widely used theory in IS, having been extensively applied in predicting and understanding acceptance of business information systems, job related applications, governments systems, e-commerce, internet banking, social networking, games as well as educational applications [29].

In [21] developed a unified acceptance theory by combining 8 past theories into one after realizing that it is more beneficial to have one theory that validated all those theories-for the use in information systems. UTAUT have 4 direct determinants of IS acceptance which are performance expectancy, effort expectancy, social influence and facilitating conditions. Those four determinants are directly related behavioural intention (BI) while $\mathrm{BI}$ is related to usage behaviour. In addition, it contains 4 moderators, namely gender, age, experience and voluntariness of use that moderate the effect of certain relationships. This study use modified UTAUT as the basis for framework development, shown in Fig. 1.

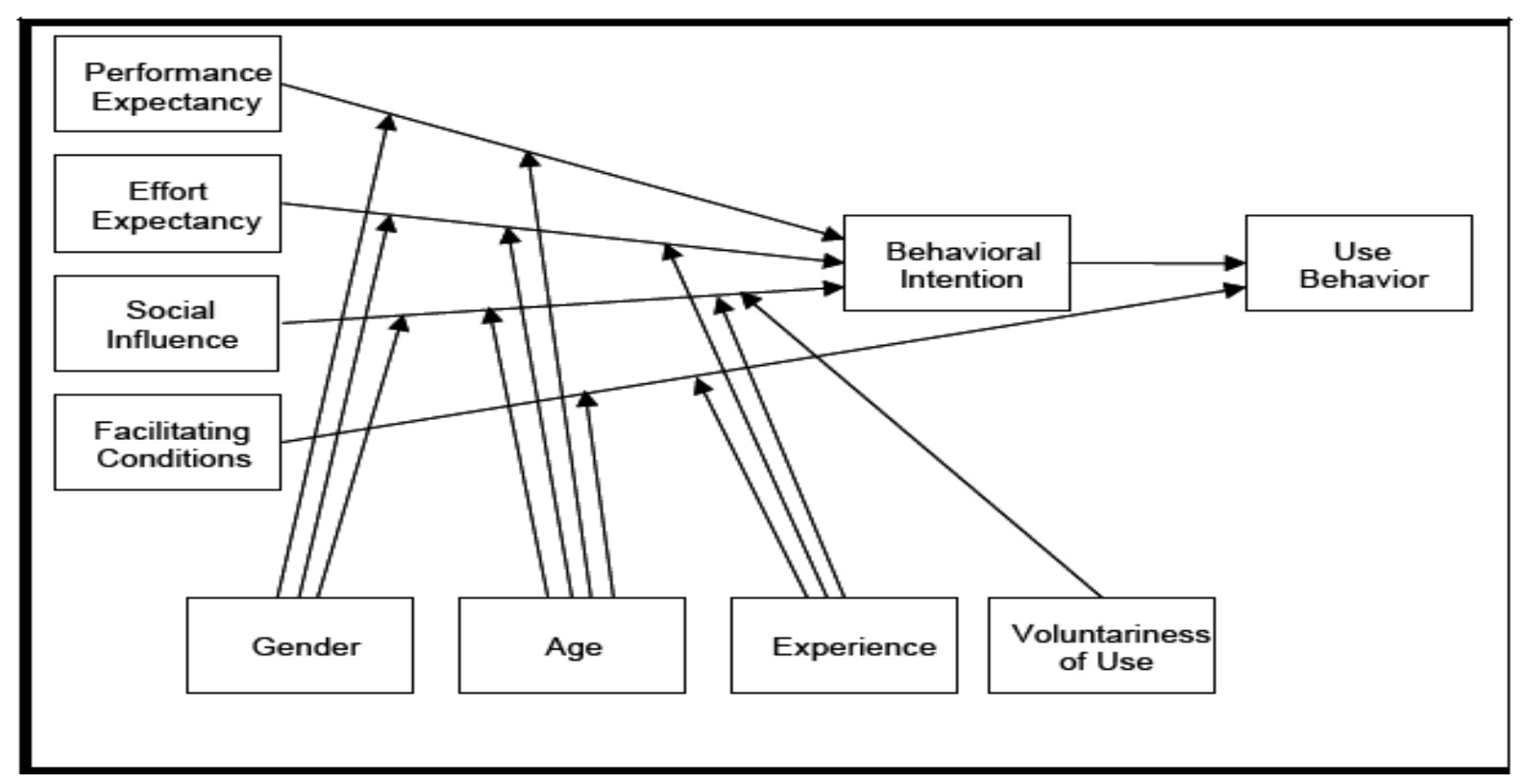

Fig.1. Unified Theory of Acceptance and Use of Technology (UTAUT) 


\subsection{Educational Games Acceptance Studies}

Understanding the user acceptance factors of educational games helps designers and developers to integrate those elements particularly during the design process. This will help to ensure success of EG development. Despite its importance, researches focusing on educational games acceptance are still very much lacking and relatively new. This is concluded upon broad review of literatures and available articles and suggestions from recent studies [21-22].

Several studies were done to understand the acceptance factors of entertainment games. In [30] have analyzed the factors that influence potential users' adoption of mobile broadband wireless access technology based games by using extended TAM. The extension includes an emotion variable together with moderating effect of gender, age and games experience. They found that the effect of perceived enjoyment was very important but usefulness did not influence the gamers' attitude. They also found that age is the key moderator of games acceptance. In another study by [31] applied extended TAM that incorporates social influences and flow experience in predicting users' acceptance of online games. Results have shown that social norms, attitude and flow experience explains about $80 \%$ of game playing. At the same time, perceived usefulness and perceived ease of use are significantly related to attitude with ease of use being a more important factor. Study by [32] found that perceived enjoyment, attitude, flow and perceived usefulness are related to intention to use social network games. In[33] found that attitude, enjoyment and subjective norms are the contributing factors towards intention to play online games while trust is not significant. In [34] found cognitive absorption and attitude were significant towards intention while social norm was found insignificant.

In [15] found that factors affected student preferences for educational games are usefulness, ease of use, learning opprotunities and experience. Effect on genders is also found that mediated by experience and ease of use. Specifically, usefulness is the main predictor of video games acceptance, followed by ease of use and learning opportunity. However, their study only measure student perceptions on possibility of educational games usage, without real use of any educational video games in particular. Therefore, usage of real games technology might 
reveal different results.

Another study by [21] investigated EGs acceptance factors among teachers using diffusion of innovation (DOI) theory. Teachers were found ready to use EG if it meet several requirements includingadvantages (effectiveness, game support features, gender neutral features, engagement and problem solving), compatibility (game alignment with the state and national standards, available time for playing the game, available computers for playing the game and the teachers' technology training), complexity (rich content, attractive game context and story, adjustment of the game difficulties) and "tryability" (accessing to a trial version of the game). In [35] have proposed several criteria for educational games design framework that related to usefulness, ease of use andbehavioural intention. It found that transfers of skills criteria and learner control criteria are significant towards usefulness while situated learning was significantly related to ease of use. However, only usefulness was significantly related to behavioural intention while ease of use was found otherwise. In [36] found that attitude, playfulness and self-efficacy were the factors related to intention to use ubiquitous video-game based learning. Study done by [37] found performance expectancy, attitude and enjoyment were significant while self efficacy and anxiety were found otherwise.

Based on above studies, similarity and contradiction were found on the significant factors Due to lack of studies in EG acceptance, we seek to further explore its constructs and measures using confirmatory factor analysis by adapting the UTAUT model. To the best of our knowledge, no study of educational game acceptance was found using UTAUT model so far. UTAUT predicts direct relationship of independent variables toward dependant variable. The following section presents the hypothesized model, adapted constructs and measures of this study together with its original sources.

\section{PROPOSED CONSTRUCTS AND MEASURES}

Based upon review of literatures and studies that utilized TAM and UTAUT for educational systems (i.e: e-learning, mobile learning and games), we proposed 6 constructs (latent independent variables) that hypothesized as related to one dependant latent variable as shown in Fig. 1. These variables were adapted from previous studies and original UTAUT model. 
The independent constructs are performance expectancy, effort expectancy, attitude, self efficacy, anxiety and enjoyment. The dependant construct is behavioral intention. We omit construct use behavior in this study since this is a newly explored technology in our institution whereby students don't have any previous experiences using the technology. Followings section describes the justification for selection of each variable and its measurement.

\subsection{Proposed Constructs: Independent Variables}

Performance expectancy (PE) is defined as "the extent to which an individual believes that using an information system will help him or her to attain benefits in job performance". Since this definition is more towards job related environment, we would like to note here that job performance here is taken as learning performance. In [28] proposed that PE which is the main predictor of IS acceptance is similar with [27]. However, in the case of games [30] found that it was not significant for online games technology. We proposed 4 measures for construct PE that was derived from followings study[27-28, 22,38].

Effort expectancy (EE) is defined as "the degree of ease associated with the use of system". It is considered the second most important factor in IS acceptance [27, 29]. It has similar meaning with ease of use in TAM model. Acceptance theory of IS proposed that in order for information system to be well accepted, it has to be easy to use. This construct is important as an extension of usability studies that was done during development phase. 4 measures were derived for EE based upon several studies[27-28, 22,38].

Attitude (Att) towards using technology is defined as "individual behaviour overall affective reaction to using a system". In [28] explained that attitude was significant towards intention to use across many studies. Similarly, in [39] also proposed that attitude will have direct effect on behavioural intention, similar with [27]. Based upon that, we derived 4 measures of attitudes from past studies [27-28, 34,40].

Self-efficacy (SE) is defined as the judgement of one's ability to use technology (which is referred to educational games as in here). Self efficacy was proposed to be significantly related to behavioural intention (BI) as in [41-42]. However, in [28]proposed that it is not directly related to BI. Therefore, we seek to retest the factor in our study. Four measures was proposed for SE as suggested by [28, 40]. Even though in [28] found that SE was not a direct 
effect on intention, other studies have proven otherwise [43].

Anxiety (Anx) is defined as emotional fear, apprehension and phobia felt by individuals towards using the technology [41]. Individuals with high degrees of technology anxiety are expected to have lower degrees of intention to use the technology. In [43] found that anxiety was significantly related to ease of use. However, new generations of learners seems to have lower anxiety towards use of computer games considering their experiences with computer and internet technologies. Thus, we retest this factor in our study and proposed 4 measures derived from [28].

Enjoyment (Enj) is defined as state of mind or an individual trait. In [45] provided empirical evidences supporting enjoyment as significantly related to intention. This is similar with other studies as well [32-33, 41]. Educational games considered as both useful and fun applications. Thus, enjoyment is one of the factors to be explored in educational games study. 5 measures were proposed based upon several studies, [30, 38, 40].

\subsection{Proposed Constructs: Dependent Variables}

As mentioned earlier, the dependant variable is behavioural intention (BI). Behavioural intention is defined as the indication of an individual's readiness to perform a given behavior [44]. It further explained that behavioral intention will lead to a specific behavior. Behavior means an individual's observable response in a given situation with respect to a given target. Three measures proposed for BI as derived from [22, 45, 40].

\subsection{Hypothesized Model}

Based upon an analysis of constructs discussed in the previous section, the hypothesized model was proposed as in Fig. 2. Both descriptive and Structural Equation Modelling (SEM) analysis using confirmatory factor analysis was performed in this investigation. As mentioned earlier, this study will only present the first part of analysis which is the proposal and confirmation of study measures. Fig. 2 shows the hypothesized model. 


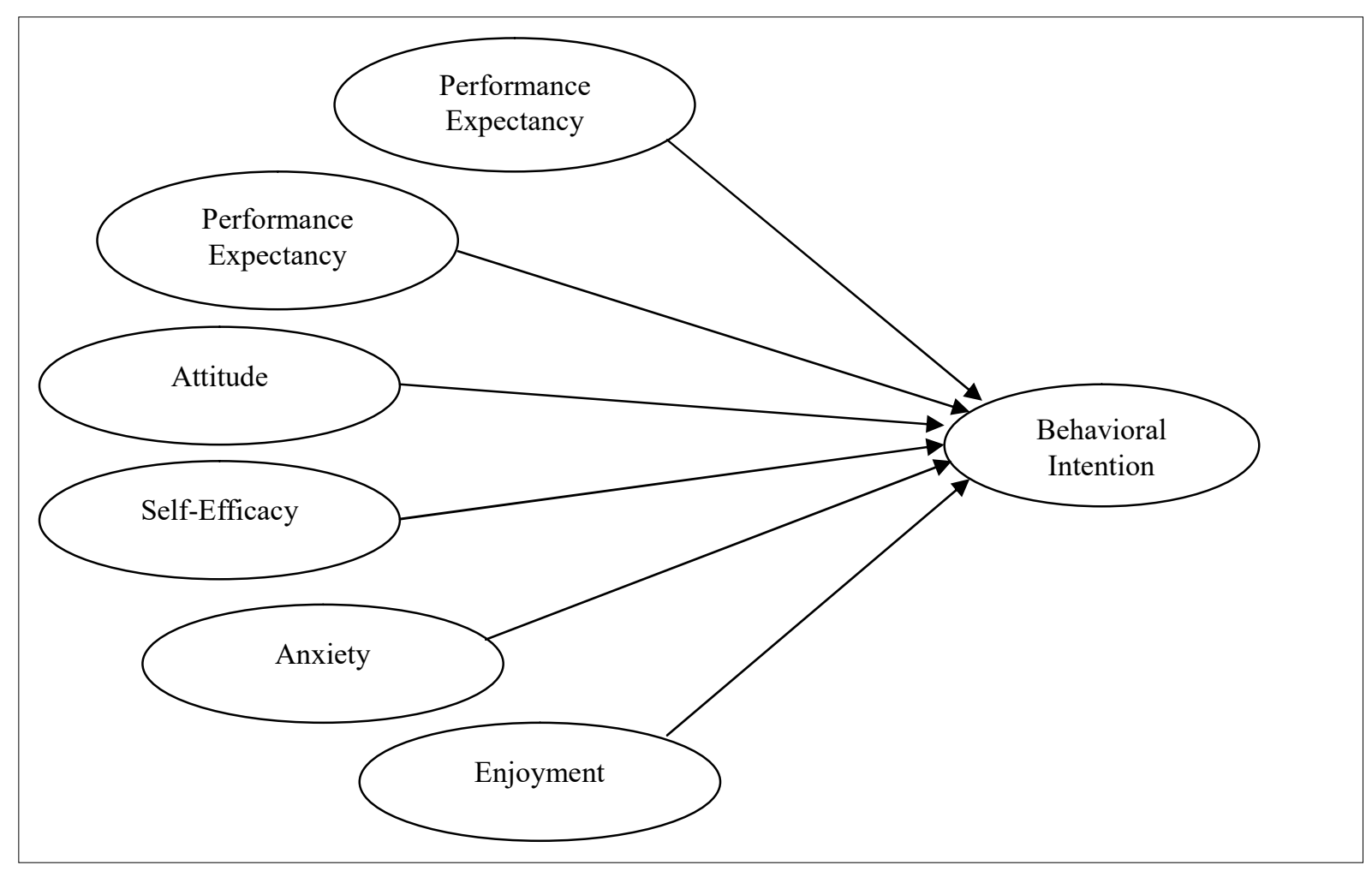

Fig. 2 Hypothesized model

\section{METHODOLOGY}

\subsection{Data Collection}

A total of 28 items were derived in this study. The items were developed into a survey form by applying Likert's method using 5 scales ranging from 1 as strongly disagree, 2 as disagree, 3 as not sure, 4 as agree and 5 as strongly agree. During the data collection process, respondents were asked to use the self developed online games for 1 to 2 hours. After they are ready to fill up the survey, the questionnaire was given to them. A total of 180 undergraduate computer science students from UniversitiTeknologi Malaysia (UTM) Kuala Lumpur and Skudai, Malaysia participated in the survey. The students never have any experiences in using online educational computer games.

\subsection{The Educational Games}

The game used in this research is a self-developed online game for learning Introductory 
Programming subject. It is consist of four mini games integrated in a main module. The content was adapted from syllabus taught at UTM with focus on C Programming basic concepts. Apart from 4 game modules, a compact notes module also developed inside the games for students' quick reference. The game was installed in the laboratory server for the data collection purpose.

\subsection{Reliability and Descriptive Analysis}

For statistical analysis, both descriptive and reliability analysis were carried out using SPSS version 17. Table 1 shows the proposed measures, mean, mode, median and standard deviations of each measure. As for the missing value, mean replacement was used based on suggested recommendation in [46]. Table 2 shows the result of reliability analysis.

Table 1. Items and descriptive analysis result

\begin{tabular}{llrrc}
\hline Items & \multicolumn{1}{c}{ Description } & Mean & Med. & Mod. \\
\hline PE1 & I would find the educational game useful in my study. & 3.91 & 4.00 & 4 \\
PE2 & Using the educational game enables me to learn the subjects & 3.87 & 4.00 & 4 \\
& more quickly. & & & \\
PE3 & Using the game increases my learning productivity. & 3.88 & 4.00 & 4 \\
PE4 & If I use the educational game, I will increase my chances of & 3.78 & 4.00 & 4
\end{tabular}

EE1 My interaction with the games would be clear and $3.81 \quad 4.00 \quad 4$ understandable.

EE2 It would be easy for me to become skillful at using the games. $\quad \begin{array}{lll}3.81 & 4.00 & 4\end{array}$

EE3 I would find the games easy to use. $\quad 3.91 \quad 4.00 \quad 4$

EE4 The games are easy to learn. $\quad 3.93 \quad 4.00 \quad 4$

$\begin{array}{llll}\text { Att1 } & \text { Using the game is a good idea. } & 4.03 & 4.00\end{array}$

Att2 The games make C Programming Subject more interesting. $\quad \begin{array}{lll}3.95 & 4.00 \quad 4\end{array}$

$\begin{array}{lllll}\text { Att3 Learning with educational games is fun. } & 4.08 & 4.00 & 4\end{array}$

$\begin{array}{lllll}\text { Att4 I like learning with the educational games. } & 3.98 & 4.00 & 4\end{array}$

I could learn the subject using the educational games...

ED1 If there was no one around to tell me what to do as I go. $\quad 3.58 \quad 4.00 \quad 4$ 
ED2 If I could call someone for help if I got stuck. $\quad 3.60 \quad 4.00 \quad 4$

ED3 If I had a lot of time to learn the content of the games. $\quad 3.60 \quad 4.00 \quad 4$

ED4 If I had just the built- in help facility for assistance. $\quad 3.59 \quad 4.00 \quad 4$

Anx1 I feel apprehensive about using the games $\quad \begin{array}{lll}2.47 & 2.00 & 2\end{array}$

Anx2 It scares me to think that I could lose a lot of information using $\begin{array}{lll}2.51 & 2.00 & 2\end{array}$ the games by hitting the wrong key.

Anx3 I hesitate to use the games for fear of making mistakes I cannot $\begin{array}{llll}2.44 & 2.00 & 2\end{array}$ correct.

Anx4 The game is somewhat intimidating to me. $\quad \begin{array}{lll}2.12 & 2.00 & 2\end{array}$

Enj1 When using the educational games, I will not realize the time $\begin{array}{llll}3.56 & 4.00 & 4\end{array}$ elapsed.

Enj2 When using educational game, I will forget the work I must do. $3.18 \quad 3.00 \quad 3$

Enj3 Using educational games will give enjoyment for my learning. $\quad \begin{array}{lll}3.85 & 4.00 & 4\end{array}$

Enj4 Using educational games will stimulate my curiosity. $\quad 3.89 \quad 4.00 \quad 4$

$\begin{array}{lllll}\text { Enj5 } & \text { Using educational games will lead to my exploration. } & 3.93 & 4.00 & 4\end{array}$

BI1 I intend to play educational games in the future. $\quad \begin{array}{lll}4.02 & 4.00 & 4\end{array}$

BI2 I predict I will play educational games in the future. $\quad \begin{array}{lll}4.02 & 4.00 & 4\end{array}$

BI3 I plan to play educational games in the future. $\quad \begin{array}{lll}4.02 & 4.00 & 4\end{array}$

Table 2. Reliability analysis

\begin{tabular}{ccc}
\hline Constructs & No of Items & Cronbach'sAlpha Value \\
\hline Performance Expectancy (PE) & 4 & 0.842 \\
Effort Expectancy (EE) & 4 & 0.845 \\
Attitude (Att) & 4 & 0.815 \\
Self-efficacy (SE) & 4 & 0.605 \\
Anxiety (Anx) & 4 & 0.887 \\
Enjoyment (Enj) & 5 & 0.735 \\
Behavioural Intention (BI) & 3 & 0.811 \\
Total number of Items & 28 & 0.849 \\
\hline
\end{tabular}

\subsection{Structural Equation Modelling}


For the purpose of measures development, a confirmatory factor analysis (CFA) was done to determine the strength of each measure or indicator loads on their construct. We used AMOS 18 for the purposes. Before confirming the model, several analyses were performed as discussed in the following. Assessment of normality was done on the collected data and it was found that the data was normally distributed with both skewness and kurtosis fall within suggested value (skewness value between -0.004 to 0.448 and kurtosis range from -0.48 to $0.705)[47]$.

Then, analysis was done on model fitness of indices. A number of fitness of indices was considered in measurement model in order to assess the fitness between collected data and hypothesized model. Three types of fit indices were used, namely absolute fit, parsimonious fit as well as incremental fit. The acceptable value for each fitness indices [48]is presented in Table 3. Findings shown that the model have a good fit with values of fit indices shown in Table 3.

Table 3. Goodness of fit indices

\begin{tabular}{ccc}
\hline Fitness of Indices & Suggested Value & Findings \\
\hline Chi-Square $\left(\chi^{2}\right)$ & The smaller the better & 580.886 \\
Ratio (cmin/df) & Less than 2 & 1.766 \\
RMSEA (Root Mean & 0.05 and below (perfect) & 0.065 \\
Square Error of Approximation) & $0.05-0.08$ (good match) & \\
Tucker Lewis Index (TLI) & Close to 1 & 0.875 \\
Comparative Fit Index (CFI) & Close to 1 & 0.891 \\
Incremental fit indices (IFI) & Close to 1 & 0.891 \\
Goodness of fit index (GFI) & Close to 1 & 0.822 \\
\hline
\end{tabular}

Fig. 3 shows the factor loadings of each measure and correlation between constructs of hypothesized framework. Double arrow represents correlation between constructs while single arrow shows factor loading for each measure. 


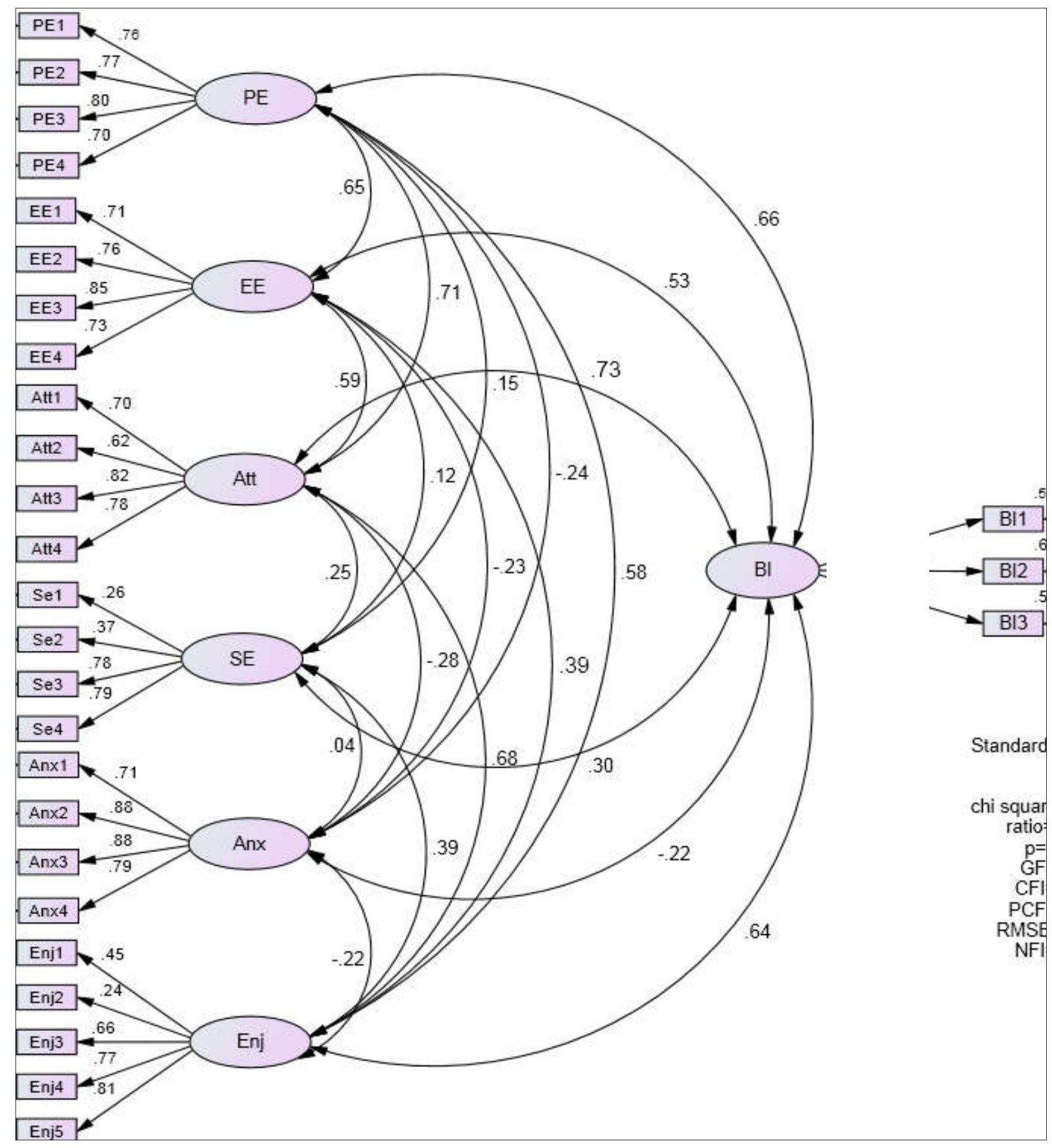

Fig.3. Confirmatory factor analysis result

Table 4 shows the factor loadings of each measure while Table 5 shows the correlations between constructs. Three measures namely Se1, Se2 and Enj2 were found to have factor loadings below the recommended value. Any measure with factor loadings less than 0.5 is not recommended for analysis [22], thus the three measures was omitted from further analysis, making only 25 valid measures left. This process is important in order to ensure convergent validity of the measures [46]. 
Table 4. Factor loading for items

\begin{tabular}{|c|c|c|c|c|c|c|c|}
\hline \multicolumn{3}{|c|}{ Relationship } & \multirow{2}{*}{$\begin{array}{c}\text { Factor Loading } \\
0.726\end{array}$} & \multicolumn{3}{|c|}{ Relationship } & \multirow{2}{*}{$\begin{array}{c}\text { Factor Loadings } \\
0.810\end{array}$} \\
\hline EE4 & $<--$ & $\mathrm{EE}$ & & Enj5 & $<--$ & Enj & \\
\hline EE3 & $<--$ & $\mathrm{EE}$ & 0.850 & Enj4 & $<--$ & Enj & 0.766 \\
\hline EE2 & $<--$ & $\mathrm{EE}$ & 0.764 & Enj3 & $<--$ & Enj & 0.663 \\
\hline EE1 & $<--$ & $\mathrm{EE}$ & 0.714 & Enj2 & $<--$ & Enj & $0.241^{*}$ \\
\hline Att4 & $<--$ & Att & 0.776 & Enj1 & $<--$ & Enj & 0.450 \\
\hline Att3 & $<--$ & Att & 0.816 & PE4 & $<--$ & $\mathrm{PE}$ & 0.702 \\
\hline Att2 & $<--$ & Att & 0.617 & PE3 & $<--$ & $\mathrm{PE}$ & 0.801 \\
\hline Att1 & $<--$ & Att & 0.701 & PE2 & $<--$ & $\mathrm{PE}$ & 0.765 \\
\hline $\mathrm{Se} 4$ & $<--$ & $\mathrm{SE}$ & 0.792 & PE1 & $<--$ & $\mathrm{PE}$ & 0.762 \\
\hline $\mathrm{Se} 3$ & $<--$ & SE & 0.785 & BI1 & $<--$ & $\mathrm{BI}$ & 0.768 \\
\hline $\mathrm{Se} 2$ & $<--$ & $\mathrm{SE}$ & $0.375^{*}$ & $\mathrm{BI} 2$ & $<--$ & $\mathrm{BI}$ & 0.779 \\
\hline Se1 & $<--$ & $\mathrm{SE}$ & $0.257^{*}$ & $\mathrm{BI} 3$ & $<--$ & $\mathrm{BI}$ & 0.759 \\
\hline Anx4 & $<--$ & Anx & 0.793 & & & & \\
\hline Anx3 & $<--$ & Anx & 0.877 & & $* \mathrm{Or}$ & ted $\mathrm{m}$ & es with low factor \\
\hline Anx2 & $<--$ & Anx & 0.878 & & & badin & 1, Se2,Enj2) \\
\hline Anx 1 & $<--$ & Anx & 0.710 & & & & \\
\hline
\end{tabular}

To ensure the discriminant validity of the constructs, in [39] recommended that the correlations between constructs are not excessively high because if so, it is difficult to measure two distinct constructs. The suggested value for correlations between construct is less than 0.9. Based on analysis, all constructs are acceptably correlated except for self efficacy (SE) and Anxiety (Anx) which have low correlation between behavioural intentions (BI). In other words, self efficacy and anxiety were not directly correlated to intention to use educational games. In addition, the two constructs were also found to have a very low correlation or negatively correlated to other constructs as well. 
Table 5. Correlation between constructs

\begin{tabular}{cccc}
\hline Constructs & Correlation Value & Constructs & Correlation Value \\
\hline $\mathrm{PE}<-->\mathrm{BI}$ & $0.661^{*}$ & $\mathrm{Att}<-->\mathrm{SE}$ & 0.253 \\
$\mathrm{EE}<-->\mathrm{BI}$ & $0.531^{*}$ & $\mathrm{EE}<-->\mathrm{SE}$ & 0.123 \\
$\mathrm{Att}<-->\mathrm{BI}$ & $0.729^{*}$ & $\mathrm{Anx}<-->\mathrm{PE}$ & -0.243 \\
$\mathrm{EE}<-->\mathrm{PE}$ & $0.650^{*}$ & $\mathrm{SE}<-->\mathrm{Anx}$ & 0.041 \\
$\mathrm{Att}<-->\mathrm{PE}$ & $0.705^{*}$ & $\mathrm{EE}<-->\mathrm{Anx}$ & -0.228 \\
$\mathrm{Enj}<-->\mathrm{BI}$ & $0.636^{*}$ & $\mathrm{Att}<-->\mathrm{Anx}$ & -0.281 \\
$\mathrm{PE}<-->\mathrm{EE}$ & $0.650^{*}$ & $\mathrm{Anx}<-->\mathrm{Enj}$ & -0.224 \\
$\mathrm{Att}<-->\mathrm{Enj}$ & $0.679^{*}$ & $\mathrm{SE}<-->\mathrm{PE}$ & 0.148 \\
$\mathrm{EE}<-->\mathrm{Enj}$ & $0.388^{*}$ & $\mathrm{SE}<-->\mathrm{Enj}$ & 0.391 \\
$\mathrm{Enj}<-->\mathrm{PE}$ & $0.585^{*}$ & $\mathrm{SE}<-->\mathrm{BI}$ & 0.302 \\
$\mathrm{EE}<-->\mathrm{Att}$ & $0.590^{*}$ & $\mathrm{Anx}<->$ BI & -0.216 \\
\hline
\end{tabular}

$* p<0.001$

\section{DISCUSSION AND CONCLUSION}

Development of accurate measures is one of the important aspects in behavioral studies. This is because having the right measures will ensure the level of accuracy of research that is being carried out. In SEM, the strength of proposed measure can be assessed using confirmatory factor analysis or measurement model. CFA is able to assess many aspects such as convergent validity and discriminant validity as suggested by [46]. Thus, using both reliability and validity are highly recommended for strengthening the research process and methodology.

This study found that 25 indicators have met the suggested requirements to be used for further analysis on educational games acceptance. 3 measures were omitted due to lower factors loading. The measures are presented in Table 1 that consists of 7 latent variables and its relationship are presented Fig. 2. After the analysis, each of the constructs is presented as follows: performance expectancy is presented by 4 measures, effort expectancy also 4 measures, attitude by 4 measures, self-efficacy by 2 measures, anxiety by 4 measures, enjoyment by 4 measures and behavioral intention by 3 measures. 
From the analysis, it was found that four factors were significantly correlated with behavioral intention namely performance expectancy (PE), effort expectancy (EE), attitude (Att) and enjoyment (Enj). Therefore, we used the four factors in our further analysis. This findings is similar to many studies such as $[27,21,30]$. In other words, students were found to perceived educational games as a technology with capabilities to help them in learning. They also perceived that educational games must be easy to use. Students also have positive attitude towards use of educational games with the correlations value among the highest. Enjoyment is also an important factor for the students to accept educational games.

Analysis also showed that two factors, anxiety (Anx) and self efficacy (SE) were not significantly correlated towards behavioral intention. It means that the two factors are not the predictors towards educational games acceptance. In other words, the students are not having problems with computer anxiety. Thus, any implementation of online educational games are not supposed to have much problem among the students. It is also shown that the students are well versed with computer technology and able to use the computer without assistance. This is similar with findings of [21].

In conclusion, this study proposed and validated measures for educational games acceptance, which presented in a framework shown in Fig. 2. Both descriptive and structural equation modeling (SEM) was used to predict the measure strength. Twenty five measures were confirmed to have strong reliability and validity after CFA was performed. Three measures were omitted due to low factor loadings. Based on correlations analysis, four constructs were found significant which are performance expectancy, effort expectancy, attitude and enjoyment. Two constructs, anxiety and self efficacy were found otherwise. However, these correlations analysis only suggest that the factors are related to behavioral intention but not their effect. Further analysis was required for that purposes which will be done in other articles. 


\section{ACKNOWLEDGEMENTS}

Authors would like to thanks UniversitiTeknologi Malaysia (UTM) and Ministry of Higher Education of Malaysia (MOHE) for sponsoring this research with vote number 47147 granted under Centre for Teaching and Learning (CTL), UTM.

\section{REFERENCES}

[1] Prensky M. Digital game-based learning. New York: McGraw Hill, 2001

[2] Scientists F. Harnessing the power of video games for learning. Summit on Educational Games. 2006

[3] Ibrahim R, Yusoff RC, Omar HM, Jaafar A. Students perceptions of using educational games to learn introductory programming. Computer and Information Science, 2010, 4(1):205-216

[4] Gee J.P. What video games have to teach us about learning and literacy. New York: MacMillan, 2014

[5] Teh CL, Fauzy WW, Toh SC. Why use computer games for learning. In1st International Malaysian Educational Technology Convention, 2007, pp. 835-843

[6] Braghirolli LF, Ribeiro JL, Weise AD, Pizzolato M. Benefits of educational games as an introductory activity in industrial engineering education. Computers in Human Behavior, 2016, 58:315-324

[7] Van-Eck R. Building artificially intelligent learning games. In D. Gibson, C. Aldrich, \& M. Prensky (Eds.),Games and simulations in online learning: Research and developments frameworks.Pennsylvania: IGI Global, 2007, pp. 793-825

[8] Becker K. The invention of good games: Understanding learning design in commercial video games. Phd thesis, Alberta: University of Calgary, 2008

[9] Ibrahim R, Jaafar A. Educational games (EG) design framework: Combination of game design, pedagogy and content modeling. InIEEE International Conference onElectrical Engineering and Informatics, 2009, pp. 293-298

[10]MayoM J. Games for science and engineering education. Communications of ACM, 2007, $50(7): 31-35$ 
[11]Virvou M, Katsionis G, Manos K. Combining software games with education: Evaluation of its educational effectiveness. Educational Technology and Society, 2005, 8(2):54-65

[12] Oblinger D G. Games and learning:Digital games have the potential to bring play back to the learning experience.Educause Quarterly, 2006, 3:5-7

[13]Moreno-Ger P, Burgos D, Martínez-Ortiz I, Sierra JL, Fernández-Manjón B. Educational game design for online education. Computers in Human Behavior, 2008, 24(6):2530-2540

[14]Kiili K. Content creation challenges and flow experience in educational games: The IT-Emperor case. The Internet and Higher Education. 2005, 8(3):183-198

[15] Treviño-Guzmán N, Pomales-García C. How can a serious game impact student motivation and learning? InIndustrial and Systems Engineering Research Conference, 2014, pp. 514-523

[16]Boyle EA, Hainey T, Connolly TM, Gray G, Earp J, Ott M, Lim T, Ninaus M, Ribeiro C, Pereira J. An update to the systematic literature review of empirical evidence of the impacts and outcomes of computer games and serious games. Computers andEducation, 2016, 94:178-192

[17]Peng W. Design and evaluation of a computer game to promote a healthy diet for young adults. Health Communication, 2009, 24(2):115-127

[18]Arnab S, Brown K, Clarke S, Dunwell I, Lim T, Suttie N, Louchart S, Hendrix M, De Freitas S. The development approach of a pedagogically-driven serious game to support Relationship and Sex Education (RSE) within a classroom setting. Computers andEducation, 2013, 69:15-30

[19]Martinovic D, Ezeife CI, Whent R, Reed J, Burgess GH, Pomerleau CM, Yang Y, Chaturvedi R. "Critic-proofing" of the cognitive aspects of simple games. Computers and Education, 2014, 72:132-144

[20]Baniqued PL, Lee H, Voss MW, Basak C, Cosman JD, DeSouza S, Severson J, Salthouse TA, Kramer AF. Selling points: What cognitive abilities are tapped by casual video games? ActaPsychologica, 2013, 142(1):74-86

[21]Kebritchi M. Factors affecting teachers' adoption of educational computer games: A case study. British Journal of Educational Technology, 2010, 41(2):256-270 
[22]Bourgonjon J, Valcke M, Soetaert R, Schellens T. Students' perceptions about the use of video games in the classroom. Computers and Education, 2010, 54(4):1145-1156

[23] Ibrahim R, Yusoff RC, Khalil K, Jaafar A. Factors Affecting undergraduates' acceptance of educational game: An application of technology acceptance model (TAM). InH. B.Zaman et al. (Eds.), International Visual Informatics Conference-Lecture Notes in Computer Science. Berlin: Springer, 2011, pp. 135-146

[24]Ibrahim R, Jaafar A. User acceptance of educational games: A revised unified theory of acceptance and use of technology (UTAUT). World Academy of Science, Engineering and Technology, 2011, 77:551-557

[25]Bourgonjon J, Valcke M, Soetaert R, De Wever B, Schellens T. Parental acceptance of digital game-based learning. Computers and Education, 2011, 57(1):1434-444

[26]Dillon A, Morris M.User acceptance of new information technology: Theories and models. Annual Review of Information Science and Technology, 1996, 14(4):3-32

[27]Davis FD. Perceived usefulness, perceived ease of use, and user acceptance of information technology. MIS Quarterly, 1989, 13(3):319-340

[28] Venkatesh V, Morris MG, Davis GB, Davis FD. User acceptance of information technology: Toward a unified view. MIS Quarterly, 2003, 27(3):425-478

[29]Maslin M., Ramlah H. User Acceptance of information technology: Understanding theories and models. Kuala Lumpur: Venton Publishing, 2008

[30]Ha I, Yoon Y, Choi M. Determinants of adoption of mobile games under mobile broadband wireless access environment. Information and Management, 2007, 44(3):276-286

[31]Hsu CL, Lu HP. Why do people play on-line games? An extended TAM with social influences and flow experience. Information and Management, 2004, 41(7):853-868

[32] Shin DH, Shin YJ. Why do people play social network games? Computers in Human Behavior, 2011, 27(2):852-861

[33] Wu J, Liu D. The effects of trust and enjoyment on intention to play online games. Journal of Electronic Commerce Research, 2007, 8(2):128-140

[34]Zhang S, Zhao J, Tan W. An optimization behavior model for online games acceptance in China. Journal of Information and Computational Science, 2010, 7(4):933-939 
[35] Yusoff A. A conceptual framework for serious games and its validation. Phd thesis, England: University of Southampton, 2010

[36] Shen CY, Chang HB, Chang WC, Wang TH. An analysis of students' intention to use ubiquitous video game-based learning system. In10th IEEE International Conference onAdvanced Learning Technologies, 2010, pp. 744-745

[37]Ibrahim R, Jaafar A, Khalil K. Habits and factors affecting undergraduates acceptance of educational computer games: A case study in a malaysian university. InInternational Conference on Informatics and Applications, 2012, pp. 404-418

[38]Wang YS, Wu MC, Wang HY. Investigating the determinants and age and gender differences in the acceptance of mobile learning. British Journal of Educational Technology, 2009, 40(1):92-118

[39] Marchewka JT, Liu C, Kostiwa K. An application of the UTAUT model for understanding student perceptions using course management software. Communications of the IIMA, 2007, 7(2):93-104

[40] Shen CY, Chang HB, Chang WC, Wang TH. An analysis of students' intention to use ubiquitous video game-based learning system. In10th IEEE International Conference on Advanced Learning Technologies, 2010, pp. 744-745

[41]Wang HY, Wang YS. Gender differences in the perception and acceptance of online games. British Journal of Educational Technology, 2008, 39(5):787-806

[42]Jong D, Wang TS. Student acceptance of web-based learning system. InInternational Symposium on Web Information Systems and Applications, 2009, pp. 533-536

[43]Bertrand M, Bouchard S. Applying the technology acceptance model to VR with people who are favorable to its use. Journal of Cyber Therapy and Rehabilitation, 2008, 1(2):200-210 [44]Ajzen I. From intentions to actions: A theory of planned behaviour.InJ. Khul, \&J. Beckmann (Eds.), Action control: From cognitions to behaviors. Berlin: Springer-Verlag, 1985,pp. 12-30

[45]Hsu CL, Lu HP. Consumer behavior in online game communities: A motivational factor perspective. Computers in Human Behavior, 2007, 23(3):1642-1659

[46]Kline R. B. Principles and practice of structural equation modeling. New York: Guilford 
Press,2015

[47] Teo T, Wong SL, Chai CS. A cross-cultural examination of the intention to use technology between Singaporean and Malaysian pre-service teachers: An application of the Technology Acceptance Model (TAM). Journal of Educational Technology and Society, 2008, 11(4):265-280

[48]Hair J. F., Black W. C., Babin B. J., Anderson R. E.Multivariate data analysis. New Jersey: Pearson, 2010

\section{How to cite this article:}

Ibrahim R, Masrom S, Yusoff R C M, Zainuddin N M M, Rizman Z I. Student acceptance of educational games in higher education. J. Fundam. Appl. Sci., 2017, 9(3S), 809-829 